\title{
A DANÇA NA PERSPECTIVA CRÍTICO- EMANCIPATÓRIA: UMA EXPERIÊNCIA NO CONTEXTO DO ENSINO MÉDIO
}

\author{
Neusa Dendena Kleinubing \\ Universidade Comunitária da Região de Chapecó, Chapecó, Santa Catarina, Brasil
}

Gizéli Servo

Universidade Comunitária da Região de Chapecó, Chapecó, Santa Catarina, Brasil

Ricardo Rezer

Universidade Comunitária da Região de Chapecó, Chapecó, Santa Catarina, Brasil

Marizete Lemes da Silva Matiello

Universidade Comunitária da Região de Chapecó, Chapecó, Santa Catarina, Brasil

\section{Resumo}

Este texto apresenta reflexões derivadas de uma pesquisa desenvolvida com jovens do ensino médio em uma escola da rede pública estadual. O objetivo é analisar uma proposta de ensino da dança para o ensino médio, com base na abordagem crítico-emancipatória (KUNZ, 1991, 2001). Essa pesquisa fundamentou-se nos princípios da pesquisa-ação como forma de intervenção e produção de conhecimento junto aos colaboradores desse estudo. Os resultados destacam a importância da inclusão da dança como conteúdo da Educação Física no ensino médio, compreendendo-a como possibilidade de articulação entre os elementos das culturas juvenis e os saberes a serem adquiridos com essa prática, visualizando um fazer na/em dança mais consciente e crítico.

Palavras-chave: Dança. Educação Física. Ensino Médio. Abordagem CríticoEmancipatória.

\section{Introdução}

$\mathrm{H}^{2}$

á tempos, duas grandes discussões perpassam a dança no contexto da Educação Física (EF) brasileira: sua legitimidade como conteúdo a ser desenvolvido na escola e os desafios vinculados a essa pretensão. Com relação à legitimidade, partimos do entendimento de que a dança é um conteúdo da EF, pois se constitui como construção cultural (VAGO, 2010) digna de ser ensinada. Quanto aos desafios, não é incomum encontrar argumentos dos professores(as) de EF escolar a respeito desse conteúdo ${ }^{1}$. Enfim, diferentes motivos dificultam a

1-Tais como: falta de espaço adequado, formação insuficiente, pequeno conheci-

Pensar a Prática, Goiânia, v. 15, n. 3, p. 551-820, jul./set. 2012 
experimentação da dança como elemento da cultura de movimento, conforme apontam Brasileiro (2003), Saraiva-Kunz (2003), Kleinubing e Saraiva (2009), entre outros.

Ao que parece, um entrave para a efetivação da dança no contexto da EF é a falta de apropriação, por parte dos docentes, de uma forma de "fazer-dança" que priorize as possibilidades criativas do aluno, cabendo ao professor, nessa perspectiva, o papel de mediador e problematizador dessa experiência ${ }^{2}$. Mesmo reconhecendo o conhecimento técnico como uma necessidade da docência, enfatizamos a importância de ensinar nas aulas mais que passos de dança que devem ser reproduzidos pelos alunos (KLEINUBING; SARAIVA, 2009).

Buscando contribuir com a efetivação desse conteúdo na EF escolar, realizamos uma pesquisa com estudantes do ensino médio, a fim de analisar uma proposta de ensino da dança para esse contexto, com base na abordagem crítico-emancipatória (KUNZ, 1991, 2001). Nessa investigação, o conteúdo da dança foi organizado a partir das categorias propostas por Kunz (2001): trabalho, interação e linguagem. Esta investigação priorizou essas categorias para o planejamento das aulas desenvolvidas, baseando-se nas premissas da pesquisa-ação (THIOLLENT, 2000) para refletir a possibilidade de a dança se configurar como conteúdo a ser vivenciado, discutido e apreendido no âmbito da EF escolar.

Inicialmente, apresentamos neste artigo os caminhos teórico-metodológicos da pesquisa. Em um segundo momento, apresentamos os principais achados da investigação e, finalizando, apresentamos os pontos de chegada desse percurso.

\section{O percurso metodológico e os sujeitos da pesquisa}

A pesquisa foi desenvolvida com o propósito de analisar uma proposta de intervenção com o conteúdo dança, ancorada nos pressupos-

mento técnico sobre este tema, dificuldade em trabalhar este conteúdo com meninos, entre outros.

2-Importante considerar que o papel docente pressupõe, como princípio fundante, conhecimento específico do conteúdo a ser ensinado, neste caso, a dança. Este pressuposto é fundamental para possibilitar o ensino daquilo que os alunos ainda não sabem. Assim, trata-se de responsabilidade docente, apresentar aos alunos "novos" elementos da cultura, "novas" formas de fazer, enfim, apresentar aos alunos conhecimentos (nesse caso, da dança) que eles ainda não possuem.

Pensar a Prática, Goiânia, v. 15, n. 3, p. 551-820, jul./set. 2012 
tos da perspectiva crítico-emancipatória, buscando indicativos de possibilidades de desenvolvimento desse conteúdo no ensino médio. Nesse sentido, este estudo encontra-se no âmbito da pesquisa qualitativa, a qual, segundo Minayo (2007, p. 21), tem por objeto "o universo da produção humana que pode ser resumido no mundo das relações, das representações e da intencionalidade" e seguiu os pressupostos da pesquisa-ação, que permite, conforme Thiollent (2000), estudar a situação problema possibilitando identificar situações em movimento no cotidiano de determinados contextos.

Os colaboradores foram estudantes do ensino médio de uma escola da rede pública estadual de Chapecó (SC). Participaram deste estudo uma turma do segundo ano, composta por 25 alunos, e uma turma do terceiro ano, composta por 26 alunos $^{3}$. Para este texto foram selecionadas falas de alguns estudantes do segundo ano, assim identificados: Skatista, Lara, Déh, Pati, Tchucão, Ricardão, Any e Marcio. Já os estudantes do terceiro ano que terão suas falas neste texto são: Ani, Pirueta, Kid, Hugo, Letti, A.A.P, Cabelinho DS e Dhy 4 .

As intervenções ocorreram no período matutino, nas terças e quintas-feiras, nas aulas de EF, no período compreendido entre setembro e novembro de 2009, totalizando 10 horas-aula trabalhadas em cada turma ${ }^{5}$. Os instrumentos utilizados para a obtenção de informações

3-Nos dois grupos os estudantes apresentavam idades entre 15 e 18 anos.

4-Por questão de espaço, as falas apresentadas ao longo do texto foram selecionadas por se relacionarem de forma direta com os objetivos deste estudo. É importante ressaltar que todos os nomes citados são fictícios, a fim de preservar a identidade dos jovens colaboradores, e foram escolhidos pelos próprios jovens.

5-Esta pesquisa foi realizada conjuntamente à disciplina de Estágio IV. Nesse componente curricular obrigatório, os acadêmicos/estagiários propõem um plano de intervenção para o contexto do ensino médio, a partir de um contato prévio com a instituição escolar e com o professor de Educação Física responsável pelas turmas destinadas ao estágio. Como refere Marques (2003, p. 95), os estágios perspectivam diminuir o hiato entre a formação profissional formal e a vida profissional, no sentido de os cursos não se enclausurarem em torre de marfim e os profissionais não se eximirem das responsabilidades de repensarem o contínuo dos processos pedagógicos e de reorganizarem suas práticas. Conforme Rezer (2010), o estágio pode ser entendido como um laboratório pedagógico convergente de diferentes disciplinas experimentadas pelos estudantes, constituindo um espaço privilegiado de interlocução entre as diferentes "Educações Físicas" (REZER, 2011), nesse caso específico, no trato com um conteúdo denominado dança.

Pensar a Prática, Goiânia, v. 15, n. 3, p. 551-820, jul./set. 2012 
foram: observação participante, plano de ação e diário de campo ${ }^{6}$. Os procedimentos da pesquisa envolveram o chamado diagnóstico (observação participante), a intervenção pedagógica (plano de ação) e as considerações trazidas pelos estudantes (descritas no diário de campo) durante o processo. Os dados surgidos desses momentos sustentam as interpretações que desenvolvemos, seguindo as orientações de Molina Neto e Triviños (2004), quando abordam a importância e a necessidade do uso de mais de uma fonte para a obtenção de informações sobre determinado contexto, buscando, assim, divergências e convergências entre as informações, no momento de sua análise.

\section{Alguns achados da pesquisa: o jovem e suas práticas corporais}

A escola é hoje entendida como espaço de (re)significação de experiências, de (re)interpretação de cultura e, nesse caminho, Vago (2010, p. 312) discute a escola como "lugar de circulação, de crítica, de (re)interpretação e de (re)produção de culturas". Mais que em qualquer outro momento da história, crianças e jovens chegam à escola com um grande número de vivências e conhecimentos prévios que foram constituídos por/em diferentes contextos. A mídia, por exemplo, pode ser considerada como uma das responsáveis pelos saberes adquiridos por essas crianças e jovens, já que

os meios de comunicação exercem um domínio sobre as representações, os discursos, o imaginário das pessoas, as emoções, os sentimentos, as decisões [...] eles elaboram e difundem valores, formas de viver, hábitos que afetam as identidades das pessoas, o sentido da vida, as relações humanas (LIBÂNEO, 2006, p. 31).

6-Para maior esclarecimento quanto à obtenção das informações: 1) observação participante - etapa de aproximação do grupo social em estudo e reconhecimento dos pressupostos teóricos norteadores da prática pedagógica da escola, expressos no Projeto Político Pedagógico; 2) plano de ação - planejamento orientador das intervenções, contendo as categorias propostas por Kunz (2001) e os conteúdos selecionados; 3) diário de campo - documento no qual foram anotados os acontecimentos advindos da intervenção como a aceitação (ou não) e reação dos alunos quanto às dinâmicas/atividades propostas e falas/depoimentos trazidos por eles, por exemplo. 
Nesse sentido, torna-se fundamental para a escola reconhecer essas influências advindas de outros âmbitos, da mídia de modo especial, pois esta desestrutura um sistema já articulado que prevê o papel do ensinar centrado na escola. Para Carrano (2008, p. 185), é importante reconhecer essas referências de aprendizagem, não como "ruído e interferência negativa", mas como "oportunidades para a criação de espaços de mediação cultural entre os diferentes mundos vividos pelos jovens alunos".

Dessa forma, compreendemos que o espaço-tempo da EF no contexto escolar pode proporcionar aos estudantes possibilidades de movimentos e experiências outras, que não sejam somente aquelas já arraigadas nesse universo ${ }^{7}$, mas que possam vivenciar práticas que passarão a pertencer ao mundo vivido. Acreditamos que é importante saber quais práticas os estudantes realizam, tanto no contexto escolar como no não escolar, pois essas informações possibilitam (re)organizar as atividades propostas nas aulas, como também servem para nos aproximar do universo dos estudantes e entender suas preferências, bem como de onde vêm as referências de suas práticas. Essa aproximação com o mundo vivido dos estudantes pode auxiliar na organização do currículo da EF na escola, permitindo olhar para o contexto no qual estão inseridos seus atores (pais, professores e alunos). Sabemos que esse movimento nem sempre é tranquilo, e tensões podem surgir, mas como afirma Vago (2010), dessas tensões pode ocorrer adesão e/ou recusa, mas nunca indiferença ${ }^{8}$.

Neste estudo, listamos, juntamente com os estudantes, quais práticas corporais eram realizadas fora da escola. Os estudantes do terceiro ano apontaram caminhadas, corridas, futebol, atividades de academia e dança. Skate, caratê, futebol, caminhadas, le parkour, motocross, rapel, escalada, trilha, capoeira, ciclismo e, novamente, dança foram citados pelos estudantes do segundo ano.

7-Por exemplo, aulas centradas apenas nas quatro modalidades esportivas mais populares: futebol, voleibol, handebol e basquete.

8-Isso implica uma relação de respeito, não de submissão, à tradição, considerando-a como ponto de partida, como arcabouço construído ao longo da história da humanidade. Conforme Rezer (2010), reconhecer a tradição como uma ponte entre o passado e o futuro, edificada no presente, permite reconhecer que as portas para o futuro, tal como referia Adorno, ainda estão em aberto. 
Nas respostas foi possível identificar a diversidade de práticas corporais vivenciadas, o que nos leva a refletir sobre a necessidade de a EF escolar abrir seu leque de conteúdos para além de práticas tradicionais. Será possível incorporar essas práticas aos conteúdos escolares? Não seria tarefa da EF problematizar e contribuir com a ampliação dos conhecimentos que os alunos possuem sobre práticas corporais?

Nisso está compreendido o interesse pelo trabalho com a dança junto dos estudantes do ensino médio, discutindo e apontando possibilidades desse conteúdo nas aulas de EF, a partir da perspectiva crítico-emancipatória, que busca a formação de sujeitos críticos e autônomos, capazes de ler a realidade e transformá-la. Isso se dá desenvolvendo três competências: a competência objetiva, conhecendo e qualificando a ação nas diferentes práticas corporais; a competência social, entendendo as relações socioculturais, problemas e contradições destas nos contextos em que se inserem; e a competência comunicativa, que compreende a comunicação como um processo reflexivo que desencadeia iniciativas do pensamento crítico (KUNZ, 2001).

Considerando a importância dessas três dimensões do/no processo de ensino- aprendizagem, entendemos que o trato com os conteúdos nas aulas de EF necessita ser/estar relacionado com a realidade vivida pelos jovens, e não descontextualizado. Isso porque os jovens devem perceber com objetividade a ligação entre o que "veem" na escola e aquilo que "veem" na sociedade em que estão inseridos, para que possam agir com autonomia, discernimento e competência sobre/com essa realidade, principalmente pelo fato de que a escola não é uma entidade metafísica, mas uma instituição edificada na/com a socieda$\mathrm{de}^{9}$.

Partindo dessas considerações, iremos a seguir discutir os achados desta pesquisa, visando articular o conteúdo da dança, as culturas ju-

\footnotetext{
9-Essa forma de entender a escola e a EF abre um leque de possibilidades para tematizar as aulas para além do saber-fazer (sem esquecer essa competência), mas proporcionar aos alunos elementos concretos para um pensar e agir com criticidade, no contexto da cultura de movimento. $O$ trabalho com a dança, nessa perspectiva, passa pelo trato didático-pedagógico, o que significa que a dança é um saber cultural, historicamente acumulado, que deve ser apresentada e criticamente estudada pelos jovens (KUNZ, 2001).
}

Pensar a Prática, Goiânia, v. 15, n. 3, p. 551-820, jul./set. 2012 
venis e a perspectiva crítico-emancipatória para o ensino da EF.

\section{O "saber-pensar" a dança: o momento da interação}

Ao iniciarmos nossa intervenção, provocamos entre os estudantes discussões a respeito de como a dança pode se constituir num espaço de expressão e comunicação de ideias e sentimentos. Nesta etapa trabalhamos com a categoria interação, na qual, a partir da tematização do conteúdo, contemplamos o saber-pensar a/na dança. Conforme Kunz (2001), essa etapa deve ser problematizadora, para que o aluno seja capaz de compreender e diferenciar os interesses individuais e subjetivos dos interesses coletivos e objetivos. Ou seja, é importante que o aluno saiba que, além de vivenciar/aprender aquilo que é de interesse próprio e imediato, é papel da $\mathrm{EF}$ oportunizar o acesso àquilo que foi historicamente construído pela humanidade, referente a esse campo do conhecimento. Dessa forma, a problematização deve caminhar no sentido de o aluno identificar aquilo que já conhece e o que ainda precisa conhecer.

Após uma discussão coletiva sobre a dança, as turmas foram organizadas em pequenos grupos para início do processo coreográfico, tarefa proposta para as aulas. Cada grupo inicialmente escolheu um tema para ser dançado, e o papel do professor neste momento foi o de problematizar: entre outras questões, quais percepções, entendimentos, os estudantes tinham a respeito do tema? Por que a escolha dessa temática?

Entre as temáticas que surgiram, podemos citar a questão da violência, que foi recorrente nas duas turmas. Justificando a escolha, Ani argumentou que "é mais fácil de trabalhar, porque é um tema que vemos todos os dias, principalmente na TV e, infelizmente, faz parte do mundo". Skatista, afirmou que "a escolha foi feita por opiniões do grupo. Foi escolhido porque é um tema forte". Contudo, também recorrente nas duas turmas, surgiu a temática "felicidade". Segundo Pirueta, essa temática foi escolhida "porque se diferencia das outras que são muito tristes e para brincar através da dança". Já Lara argumenta: "escolhemos felicidade, alegria, porque envolve tudo o que acontece ao nosso redor".

Partindo dessa conversa, solicitamos que, dentre as opções que tínhamos de música, escolhessem a que melhor se encaixava nas aspirações de cada grupo. Essa escolha foi tensa, já que várias opiniões e 
gostos musicais se confrontaram e, muitas vezes, chegar a um consenso significa abrir mão do gosto individual. Importante destacar que, até o quarto encontro, todos os grupos já tinham definido sua música. Assim, tornou-se mais fácil pensar nos movimentos para a coreografia $^{10}$.

Para contribuir com o processo de composição da coreografia, a cada aula os alunos aprendiam novos conhecimentos sobre dança e seus aspectos coreológicos, tais como: fatores de movimento (peso, tempo, espaço e fluência), família de movimento da dança (corridas, caminhadas, saltos, giros e quedas) e expressividade. Através de pequenas dinâmicas realizamos vivências, ora de forma individual, ora nos pequenos grupos, fazendo uso dos conhecimentos já trabalhados que, aliados à temática, dariam forma à coreografia.

Mesmo com as discussões e explicações desses elementos, alguns jovens questionaram se não iríamos assistir a alguns vídeos e/ou clipes para aprenderem outros movimentos. Nesse processo, Kid argumentou que "é difícil criar passos de dança sem ver ninguém dançar, não sabemos por onde começar". Depois de ajudá-los a entender melhor o que já havíamos trabalhado e dando algumas sugestões, o grupo começou a pensar nos movimentos, demonstrando um pouco mais de motivação.

Alguns jovens destacaram a dificuldade de trabalhar em grupo. Déh afirmou que "foi um pouco confuso no começo, nem todos vinham para aula, e nem todos participaram, levavam na brincadeira, mas depois fomos nos ajudando e deu tudo certo". Nesse mesmo sen-

10-Apesar de termos clareza que os passos de dança não necessariamente precisam seguir o ritmo ou a letra da música, percebemos que para os estudantes participantes desta pesquisa essa foi condição primeira para que começassem a desenvolver o trabalho.

11-Aqui, percebemos as diferentes tensões oriundas de trabalhos em grupo (a dificuldade de acolher a sugestão do outro, a posição pessoal de atrapalhar o processo, a consolidação da ideia do que fazer, a necessidade de negociação, entre outros). Neste processo foi possível perceber como o trabalho em grupo pode ser importante, pois os alunos passam a superar os desafios juntos e passam a entender que são importantes para o processo, no caso, a composição coreográfica. Acreditamos que as dificuldades de trabalhar no coletivo estão relacionadas à dificuldade de comunicação, mas também à resistência ao que é novo. Como exemplo, um menino apresentou essa resistência e tomou a atitude de afastar-se, afirmando que não concordava com a música escolhida pelo seu grupo, passando a integrar outro.

Pensar a Prática, Goiânia, v. 15, n. 3, p. 551-820, jul./set. 2012 
tido, Pati afirma: "tivemos bastante dificuldade em montar a coreografia, mas obtivemos um bom resultado trabalhando em grupo"11.

Ao final do processo com a turma do terceiro ano, questionamos sobre a história da coreografia construída e como foi dançá-la. Ani destacou que a coreografia "foi feita em grupo, com a opinião de todos. Escolhemos a temática da violência porque esse problema está cada dia mais presente na sociedade". Para Hugo, o processo coreográfico "foi muito difícil, porque os passos tinham que envolver a temática e o ritmo. Foi uma nova experiência". Percebemos que os estudantes sentiram-se desafiados com essa proposta de construção em dança, já que fugiu do que estavam acostumados a ver/fazer. Acreditamos que esse desafio possibilitou aos jovens uma oportunidade de vivenciar novas formas de ver/fazer/pensar a dança, nas quais seus conhecimentos foram valorizados ao mesmo tempo em que aprenderam novos elementos, tanto no que se refere às técnicas, como no que se refere aos valores.

Algumas falas dos jovens do segundo ano revelam essa ideia. Segundo Tchucão, "a coreografia foi feita com algumas dificuldades, mas depois o grupo conseguiu trabalhar nela com mais intensidade. Dança para mim foi a aprendizagem de trabalhar em grupo". Para Ricardão, "a temática escolhida foi uma opção do grupo inteiro, pois todos gostaram do tema, cada um ajudava com uma ideia e a coreografia ficou espontânea".

Esses relatos remetem a Kunz (2001, p. 31), quando argumenta que o aluno

deve ser capacitado para sua participação na vida social, cultural e esportiva, o que significa não somente a aquisição de uma capacidade de ação funcional, mas a capacidade de conhecer, reconhecer e problematizar sentidos e significados nesta vida, através da reflexão crítica.

Quando Kunz (2001) se refere ao "se-movimentar", quer dizer que não devemos olhar somente para o movimento que os alunos estão realizando, mas para toda subjetividade que envolve os alunos em movimento. Com relação ao nosso trabalho, mesmo considerando as dificuldades (apontadas por nós e pelos estudantes), foi possível perceber o quanto a dança se tornou significativa, já que os alunos não 
poderiam realizar somente passos de dança, mas poderiam revelar suas ideias, seus sentimentos com relação à temática dançada. Daí o surgimento de uma reflexão mais crítica com relação ao fazer e ser sujeito da ação em dança.

\section{O "saber-fazer": aprendendo os conhecimentos sobre dança}

A competência objetiva, o saber-fazer, é discutida por Kunz (2001) a partir da categoria trabalho. Isso significa dizer que deve ser possibilitado ao aluno, com base em toda sua vivência e conhecimento, desenvolver e aprimorar habilidades, buscando a superação de seus limites, através do controle racional e do planejamento de suas ações de forma autônoma e crítica. Em síntese, essa categoria pode ser definida pela experimentação individual e coletiva, na qual o professor tem a possibilidade de conhecer melhor as experiências e vivências corporais trazidas pelos alunos, criando diversas situações de movimento com a utilização, ou não, de materiais.

Em nossa intervenção, essa perspectiva esteve presente nos aspectos coreológicos da dança: os fatores de movimento, a família de movimentos, bem como os diferentes níveis em que esses movimentos podem ser realizados (baixo, médio e alto) e a importância da expressividade na dança. Essas vivências foram realizadas ora de forma individual, ora em pequenos grupos.

Essa categoria foi muito importante na nossa proposição, já que os estudantes puderam identificar os inúmeros conhecimentos relacionados à dança. Conheceram as diferentes formas de ocupação do corpo no espaço, as dinâmicas que podem ser realizadas em cada movimento e que estas dependem da intencionalidade do movimento. Da mesma forma, perceberam que a expressividade também é importante na composição coreográfica e, ao se apropriarem desses conhecimentos, compreenderam que a realização da dança vai além da mera execução de passos. Esses novos conhecimentos, ou esse novo olhar sobre a realização da dança, foram revelados em relatos como os de Pati, Letti e Any, respectivamente: "aprendemos as noções de espaço, tempo, passos diferentes, também as expressões no momento da dança, enfim, muitas coisas novas, diferentes e interessantes"; "aprendemos que a dança é mais do que simples movimento, é também uma forma de expressão dos sentimentos"; "vimos sobre os elementos da família de movimentos e começamos a 'aplicar eles' na nossa coreografia. Apli- 
camos a corrida, o salto, o giro e a queda na nossa dança. A aula foi bem produtiva".

Percebemos como foi importante para os estudantes conhecerem os aspectos coreológicos da dança, tanto que já se expressavam utilizando os termos técnicos do processo coreográfico. Dessa forma, torna-se possível a ampliação da autonomia dos alunos, pois, a partir do momento em que se apropriam desses conhecimentos, passam a utilizálos em diferentes situações de dança e da própria vida, já que "do trabalho com a dança, da sua vivência e experimentação, deve-se resultar a construção de conhecimentos e, deste processo, devem-se resultar conhecimentos a respeito de si-mesmo, a respeito da dança e do mundo" (KLEINUBING, 2009, p. 68).

Nesse sentido, conforme observamos e pelos relatos dos próprios estudantes, identificamos um aumento significativo do conhecimento relativo à dança, bem como nos modos de auto-organização, a ponto de produzirem a dança de forma coletiva. Entendemos que esse processo desencadeou a qualificação para os jovens atuarem "dentro de suas possibilidades individuais e coletivas e agir de forma bem-sucedida no mundo do trabalho, na profissão, no tempo livre" (KUNZ, 2001, p. 40) e, no caso, na dança.

\section{"Saber-sentir" na dança: o corpo que fala e expressa}

Neste tópico, abordaremos a competência comunicativa, o sabersentir, que representa a categoria linguagem, traduzida pela fala, pela expressão de coisas, fatos e, principalmente, pelo movimento. Para que essa categoria se tornasse presente, trabalhamos com um elemento que consideramos muito importante para a coreografia: a expressividade. Segundo Gallina (2008, p.10) a expressividade na dança pode ser definida como sendo "uma forma significativa de comunicação corporal [...] inerente ao ser humano, que comunica alguma mensagem, da mesma forma que busca, através da dança, a harmonia das suas formas biológica, cultural e filosófica".

Nesse sentido, Soares et al. (1998, p. 16-17) entendem o seguinte:

Gestos e movimentos são expressão humana e esta é tudo aquilo que exceder o movimento meramente mecânico. E é esta transcendência do puramente biomecânico que nos faz humanos, capazes de observar e criar e desenvolver possibilidades de movimentos bastante 
diferenciados, contudo conscientes de uma gestualidade expressiva e significativa.

Compartilhando dessas compreensões, conversamos com os estudantes a respeito da expressividade na dança, bem como proporcionamos várias situações nas quais deveriam expressar sentimentos/sensações. Ao final dessas atividades conversamos sobre as experiências, as dificuldades encontradas, sendo a vergonha e o não saber-fazer as principais questões levantadas. Nisso lembramos as discussões de Saraiva-Kunz (2003), sobre a vergonha sentida quando percebemos os olhares dirigidos ao nosso corpo. Diferentemente dos esportes, nos quais os olhares voltam-se, por exemplo, para o objetivo do arremesso ou chute, ou seja, para a trajetória percorrida pela bola arremessada ou chutada, na dança, os olhares se voltam para o sujeito quando na expressão do seu corpo, da sua corporeidade. E aí surge um sentimento de desproteção, de exposição ${ }^{12}$.

Ao serem questionados sobre o que ficou de mais significativo após suas vivências, A.A.P destacou que "foi interessante, porque proporcionou conhecimentos e tivemos capacidade de desenvolver a dança com nosso corpo". Cabelinho comentou que foi "ótimo, pois nos mostrou várias formas de dança e que através da dança é possível a expressão dos sentimentos, opiniões". Os estudantes consideraram importante a expressão na dança destacando que "a dança faz com que expressemos o que sentimos através dos movimentos" (DS). Déh e Marcio complementaram dizendo: "aprendemos que nem todas as músicas e nem todos os passos combinam com o estilo de dança, e que para cada passo, para cada expressão existe um porque, existe um motivo" e "o que eu mais gostei foi aprender coisas novas".

É interessante ressaltar o envolvimento gradual dos jovens durante o processo; mesmo aqueles que se mostraram resistentes no início da intervenção, falaram sobre sua evolução. Kid concluiu que "somos capazes, mas temos vergonha de demonstrar" e Dhy considerou que

12-Importante destacar que, mesmo em meio a sentimentos como esses, em meio à discussão sobre expressividade, percebemos que os grupos não estavam preocupados em expressar a intencionalidade da temática. O que queriam mesmo era realizar os movimentos, justificando que faltava pouco tempo para a apresentação. Mesmo assim, procuramos fazê-los pensar sobre como deveriam olhar, se deveriam sorrir ou ficar sérios, de acordo com a "intencionalidade" que tinham com relação à música e ao tema escolhido. 
"a dança sempre esteve presente, mas ainda não tínhamos parado para observar o bem que traz à nossa vida".

Uma das falas que chamou a atenção foi a de um menino, praticante de skate. Nas aulas que observamos, dias antes de começar a intervenção, notamos que ele não participava da aula de handebol, pois dizia que não gostava muito de esportes coletivos, e dessa forma ficava andando de skate no lado de fora da quadra. Durante as aulas de dança ele participou da construção da coreografia, mas sem dar muitas sugestões; porém, quando questionado sobre o que gostou e/ou aprendeu, respondeu que "dança é a arte de se expressar com movimentos e coreografia é o conjuntos desses movimentos. Aprendi a dar mais valor à dança, e que é mais legal do que se pensa" (Skatista).

Com isso, podemos apreender que, quando alguns alunos alegam não gostar de dançar, nem sempre é um juízo adquirido pela vivência, mas, sim, por falta de conhecimentos a respeito dessa linguagem, afinal, geralmente gostamos de fazer aquilo que conhecemos. Nesse sentido, Kleinubing (2009, p. 69) argumenta que

como para o desenvolvimento dos esportes há que se ter/construir um conhecimento básico sobre seus fundamentos, para o desenvolvimento do processo coreográfico, ou seja, da dança, também é necessário ter conhecimentos sobre elementos básicos que a constituem. São esses conhecimentos que possibilitam a ampliação da capacidade criativa e expressiva na dança.

Estar abertos aos questionamentos e comentários dos estudantes favoreceu a criação de uma atmosfera de segurança com relação àquilo no que estávamos trabalhando. Aprender elementos básicos da dança possibilitou aos envolvidos discutir e refletir acerca desse fenômeno no contexto escolar e não escolar, bem como ampliou a ideia sobre a própria dança, pensando-a para além da simples execução de passos. Nesse sentido, conforme aponta Kunz (2001), conduzir o processo de ensino na abordagem crítico-emancipatória, enfatizando o diálogo e discussões, possibilita ao aluno ler, interpretar e criticar o fenômeno sociocultural da dança.

\section{Considerações finais}

Refletindo sobre o processo dessa investigação, podemos verificar 
que este estudo possibilitou aos jovens falar de suas experiências, do que os preocupa e/ou os alegra, refletidos nas temáticas tratadas nas coreografias. Também percebemos que quando os estudantes fizeram uso dos movimentos que utilizavam para as práticas (esportivas ou não) que costumam vivenciar fora da escola, demonstraram estar mais à vontade e motivados a colaborar com o processo coreográfico. Nesse sentido, acreditamos ser fundamental levar os elementos que identificam as culturas dos estudantes fora do ambiente escolar para dentro das aulas de EF, pois, como vimos, os jovens passaram a se identificar com esses elementos e se sentiram participantes do processo.

Também entendemos que a aquisição de conhecimentos relacionados ao processo coreográfico proporcionou um novo olhar para a dança, ampliando as possibilidades de "fazer dança", ao tratarem de questões presentes no universo juvenil.

Nesse processo, as categorias elaboradas por Kunz (2001) - trabalho, interação e linguagem - auxiliaram na organização pedagógica para o desenvolvimento da dança. As trocas de experiências durante a tematização, a problematização e a construção do conhecimento específico da dança deram suporte para compreendê-la como forma de expressão e linguagem. Podemos afirmar, pelas situações observadas e pelas declarações dos estudantes, que a partir do domínio de saberes ligados à dança eles foram capazes de agir com base nos conhecimentos adquiridos e puderam "ousar" quando sugeriram "novos caminhos de movimentos" para as temáticas dançadas.

Enfim, podemos considerar que, apesar do curto tempo em que estivemos em campo, foi possível visualizar possibilidades para legitimar a dança como componente curricular da EF no ensino médio e que a desconfiança e a recusa iniciais se transformaram em envolvimento na medida em que os jovens estabeleciam relações com os saberes próprios da dança e suas experiências vividas. Acreditamos que o trabalho com a dança na perspectiva crítico-emancipatória permite assumir o compromisso de olharmos para o universo juvenil e articularmos os conteúdos e objetivos da $\mathrm{EF}$, a fim de que essa prática possa se tornar mais significativa para os jovens.

Da mesma forma, reforçamos a importância do estágio como um laboratório pedagógico, no qual a possibilidade de intervenção dos estudantes, em um contexto formal, permite diferentes experiências, possibilitando um reflexo do processo de formação inicial dos estudantes. 
Finalizando, apresentamos neste artigo uma síntese desse processo investigativo. Muitos outros elementos, por questões de espaço, ficaram fora destes escritos. Destacamos nestas linhas finais que compreendemos as dificuldades que necessitamos superar para que a dança se faça presente na EF como um conteúdo a ser tratado em aula. Não obstante, entendemos que o argumento da "não aceitação dos alunos", motivo recorrente para não trabalhar esse conteúdo nas aulas, pode ser revisto, já que os estudantes se mostraram abertos a novos saberes e, principalmente, visualizaram a dança como prática possível e importante no âmbito da EF. Da mesma forma, o papel docente nesse processo pode ser redimensionado, ampliando o espectro de intervenção, perspectivando um processo de ensinar-aprender dança como uma forma de ampliar o diálogo dos sujeitos com os outros e com mundo, permitindo um maior "conhecimento-de-si".

The dance in perspective critical-emancipated: one experience in the high school context

\begin{abstract}
This paper presents reflections derived from a study with young students in a public school. The aim is examine a proposal for teaching dance for High School, based on the critical-emancipated theory (KUNZ, 1991, 2001). This research was based on the principles of action-research as a form of knowledge production and intervention with the collaborators in this study. The results pointed to the importance of dance inclusion as the content of physical education in High School, understanding it as a possible link between the elements of youth culture and knowledge to be gained from this practice, by viewing one make in dance more conscious and critical.
\end{abstract}

Keywords: Dance. Physical Education. High School. Critical-Emancipated Theory.

\title{
La danza en perspectiva crítico-emancipatoria: una experiencia en contexto de enseñanza media
}

\section{Resumen}

En este texto se presentan reflexiones derivadas de una investigación desarrollada con jóvenes en una escuela de red pública estadual y tiene como objetivo analizar una propuesta de danza para Enseñanza Media con enfoque crítico-emancipatoria (KUNZ, 1991, 2001). Este trabajo se fundamenta en los princípios de "pesquisaação" como forma de intervención y producción de conocimientos desarrollado junto a los colaboradores de este estudio. Los resultados obtenidos destacan la importancia de la inclusión de la danza al contenido de la educación física de enseñanza media, integrando estos elementos y conocimientos a la cultura de los 
jóvenes, y de esta forma lograr en ellos un pensamiento más consciente y crítico de la danza.

Palabras clave: Educación Física. Enseñanza Media. Enfoque Crítico-Emancipatoria.

\section{Referências}

BRASILEIRO, L. T. O conteúdo "dança" em aulas de Educação Física: temos o que ensinar? Pensar a Prática, Goiânia, v. 6, n. 1, p 45$58,2003$.

CARRANO, P. Identidades culturais juvenis e escolas: arenas de conflitos e possibilidades. In: MOREIRA, A. F.; CANDAU, V. M. (Org.). Multiculturalismo: diferenças culturais e práticas pedagógicas. Petrópolis: Vozes, 2008. p.182-211.

GALLINA, E. P. A expressividade dos acadêmicos de educação fisica que cursam a disciplina de metodologia do ensino da dança escolar. 2008. 96 f. Dissertação (Mestrado em Ciências do Movimento Humano) - Universidade Federal do Rio Grande do Sul, Porto Alegre, 2008.2 Disponível em: $<$ http://www.lume.ufrgs.br/bitstream/handle/10183/13808/000655455.pdf? sequence=1>. Acesso: 22 nov. 2009.

KLEINUBING, N. D. A dança como espaço-tempo de intersubjetividades: possibilidade da Educação Física no ensino médio. 2009. 136 f. Dissertação (Mestrado em Educação Física) - Universidade Federal de Santa Catarina, Florianópolis, 2009.

KLEINUBING, N. D; SARAIVA, M. C. Educação Física escolar e dança: percepções de professores no ensino fundamental. Movimento, Porto Alegre, v. 15, n. 4, p. 193-214, out./dez. 2009.

KUNZ, E. Educação Física: ensino e mudança. Ijuí: Unijuí, 1991.

KUNZ, E. Transformação didático-pedagógica do esporte. 4. ed. Ijuí: Unijuí, 2001.

LIBÂNEO, J. C. Cultura jovem, mídias e escola: o que muda no trabalho dos professores? Revista Educativa, Goiânia, v. 9, n. 1, p. 2546, jan./jun. 2006. 
MARQUES, M. O. Formação do profissional da educação. Ijuí: Unijuí, 2003.

MINAYO, M. C. Pesquisa social: teoria, método e criatividade. 25. ed. Petrópolis: Vozes, 2007.

MOLINA NETO, V.; TRIVIÑOS, A. N. S. (Org.). A pesquisa qualitativa na Educação Física: alternativas metodológicas. 2. ed. Porto Alegre: UFRGS/Sulina, 2004.

REZER, R. O trabalho docente na formação inicial em Educação Física: reflexões epistemológicas. 2010. 394 f. Tese (Doutorado em Educação Física) - Universidade Federal de Santa Catarina, Programa de Pós-Graduação em Educação Física, Florianópolis, 2010.

REZER, R. Um diálogo com diferentes "formas-de-ser" da Educação Física contemporânea: duas teses (não) conclusivas. Pensar a Prática, Goiânia, v. 14, n. 2, p. 1-14, 2011.

SARAIVA-KUNZ, M. C. Dança e gênero na escola: formas de ser e viver mediadas pela educação estética. 2003. $420 \mathrm{f}$. Tese (Doutorado em Motricidade Humana na especialidade de Dança) - FMH/UTL, Lisboa, 2003.

SOARES, A. et al. Improvisação \& dança: conteúdos para a dança na educação física. Florianópolis: UFSC, 1998.

THIOLLENT, M. Metodologia da pesquisa-ação. 10. ed. São Paulo: Cortez, 2000.

VAGO, T. M. Educação física e a cultura escolar: notas de reflexão. In: SANTOS, L. L. et al. Convergência e tensões no campo da formação e do trabalho docente. Belo Horizonte: Autêntica, 2010. p. 311-324.

Recebido em: 31/05/2011

Revisado em: 09/10/2011

Aprovado em: 03/02/2012

Endereço para correspondência

neusadk@gmail.com

Neusa Dendena Kleinubing

Pensar a Prática, Goiânia, v. 15, n. 3, p. 551-820, jul./set. 2012 
DOI 10.5216/rpp.v15i3.14532

Fundação Universitária do Desenvolvimento do Oeste Fundação Universitária do Desenvolvimento do Oeste

Rua Senador Atílio Fontana, 591-E, Efapi

Chapeco, SC - Brasil 